\title{
Originals
}

\section{Possible Mechanism by which Somatostatin-Induced Glucagon Suppression Improves Glucose Tolerance during Insulinopaenia in Man}

\author{
J. E. Liljenquist, Z. T. Bloomgarden, A. D. Cherrington, J. M. Perry, and D. Rabin
}

Howard Hughes Medical Institute Laboratories, Departments of Medicine and Physiology, Vanderbilt University School of Medicine, Nashville, Tennessee, USA

\begin{abstract}
Summary. The present study examines the question of whether lowering the basal plasma glucagon concentration alters the response of the liver to an intravenous glucose load under conditions where insulin is present at near-basal concentrations. Acute hyperglycaemia of $220-240 \mathrm{mg} / \mathrm{dl}$ was induced by peripheral venous glucose infusion in two groups of normal men who had undergone hepatic vein catheterization. Somatostatin $(0.9 \mathrm{mg} / \mathrm{h})$ was infused in both groups together with an infusion of insulin $(0.15 \mathrm{mU} / \mathrm{kg} / \mathrm{min})$ to maintain arterial insulin levels at $7-12 \mu \mathrm{U} / \mathrm{ml}$. Glucagon $(1.5 \mathrm{ng} / \mathrm{kg} / \mathrm{min})$ was infused in one group resulting in a rise in plasma glucagon levels from $148 \pm 37$ to $228 \pm 25 \mathrm{pg} / \mathrm{ml}$, thus mimicking basal portal glucagon concentrations, whereas in the second group glucagon was not replaced, resulting in a fall in circulating glucagon levels from $132 \pm 21$ to $74 \pm 15 \mathrm{pg} / \mathrm{ml}$. In the glucagon-deprived group, net splanchnic glucose production (NSGP) fell from $143 \pm 31$ to $-72.5 \pm 39 \mathrm{mg} /$ min $(\mathrm{p}<0.01)$, indicating that net splanchnic glucose uptake had occurred. By contrast, NSGP did not change significantly ( $137 \pm 20$ vs $151 \pm 60 \mathrm{mg} / \mathrm{min})$ in the group in which both insulin and glucagon were replaced during hyperglycaemia. These data thus suggest that during hyperglycaemia, when the insulin concentration is fixed at basal levels, glucagon may play an important role in determining whether or not the liver diminishes its output of glucose and stores glucose in response to a glucose load.
\end{abstract}

Key words: Glucagon, insulin, somatostatin, hyperglycaemia, net splanchnic glucose production, hepatic vein catheterization.
Whether somatostatin administration improves plasma glucose control in insulin-requiring diabetics by suppressing circulating glucagon or only by delaying intestinal glucose absorption is contraversial [1-3]. Since glucagon has been shown to play a major role in the maintenance of hepatic glucose production [4] and yet to be virtually devoid of effects on peripheral glucose metabolism [5], any beneficial lowering of postprandial glucose excursions in diabetics attributable to suppression of plasma glucagon levels would most likely be mediated in the liver. Thus, lowering the circulating glucagon level would alter the ability of the liver to handle an incoming glucose load. The present study was designed to investigate this hypothesis.

\section{Methods}

Eleven healthy, non-obese men between the ages of 18-44 years were studied. None of these subjects were receiving any medication. All were within $10 \%$ of ideal body weight and mean body weight was $71.5 \mathrm{~kg}$. Studies began between 12 noon and $2 \mathrm{p} . \mathrm{m}$. after a $12-14 \mathrm{~h}$ fast. The subjects were all placed on a $200 \mathrm{~g}$ carbohydrate diet for 3 days prior to study. The protocol for this study was reviewed and approved by the Vanderbilt University Committee for the Protection of Human Subjects. The nature, purpose, and possible risks of the procedure were fully explained to each subject before obtaining his voluntary consent.

Hepatic venous and brachial artery catheterizations were performed in all subjects as previously described [6]. After a 30 minute basal period, three types of perturbation were induced. In Protocol I four subjects received somatostatin $(0.9 \mathrm{mg} / \mathrm{h})$ and insulin $(0.15 \mu \mathrm{U} / \mathrm{kg} / \mathrm{min})$ via a peripheral vein for $2 \mathrm{~h}$. In Protocol II, three additional subjects received somatostatin and insulin as in Protocol I, and in addition were infused with glucagon $(1.5 \mathrm{ng} / \mathrm{kg} /$ $\mathrm{min}$ ). In both groups the plasma glucose concentration was raised to $220-240 \mathrm{mg} / \mathrm{dl}$ simultaneous with the hormone infusions. Hyperglycaemia was maintained by a variable glucose infusion using the glucose clamp technique of Andres et al. [7]. Thus, hyperglycaemia and low levels of insulin were maintained in both 


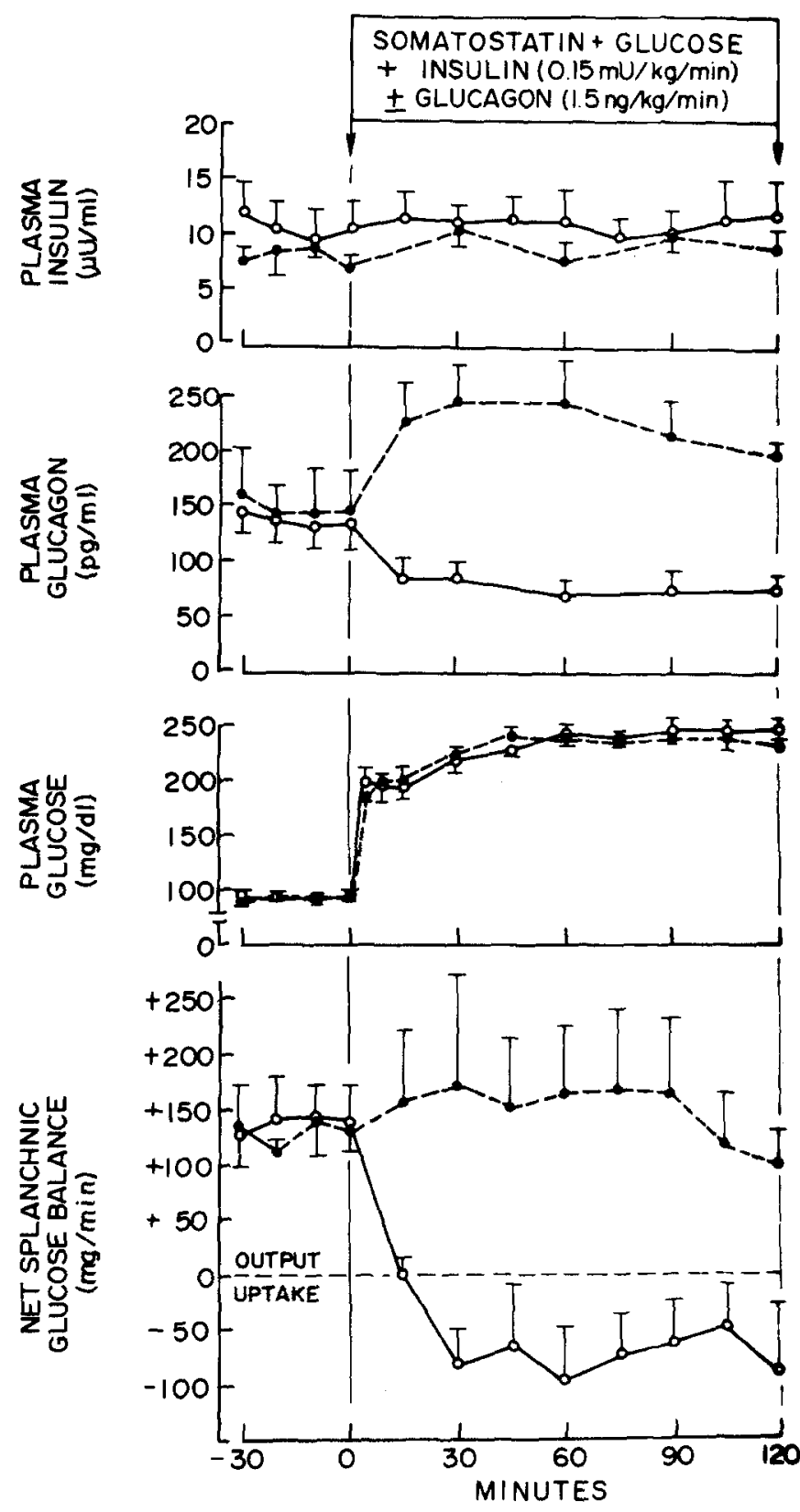

Fig. 1. The effects of infusions of somatostatin and insulin on the arterial plasma insulin levels in two groups of normal men are shown in the top panel. Glucagon was infused in one group $(---))(n=3)$ and not in the other $\left(\mathrm{O}^{-} \mathrm{O}\right)(\mathrm{n}=4)$ producing the arterial glucagon levels seen in the second panel. Exogenous glucose was infused at a variable rate in both groups so as to achieve similar levels of hyperglycaemia (third panel). The effect of these perturbations on net splanchnic glucose balance is seen in the bottom panel. Bars represent SEM

protocols, but with glucagon secretion suppressed in Protocol I and with the hormone replaced in Protocol II. In Protocol III, four subjects, serving as controls, received a $2 \mathrm{~h}$ saline $(0.154 \mathrm{~mol} / \mathrm{l})$ infusion.

To measure estimated hepatic blood flow (EHBF) indocyanine green was administered as a constant intravenous infusion beginning $45-60$ minutes prior to the 30 minute basal period. This
Table 1. The effect of glucagon withdrawal and replacement on net splanchnic glucose balance under conditions of hyperglycaemia and fixed low levels of insulin

\begin{tabular}{llll}
\hline Protocol & $\mathrm{n}$ & $\begin{array}{l}\text { Basal period } \\
\mathrm{mg} / \mathrm{min}\end{array}$ & $\begin{array}{l}\text { Study period } \\
\mathrm{mg} / \mathrm{min}\end{array}$ \\
\hline I $\begin{array}{l}\text { Somatostatin }+ \\
\text { Hyperglycaemia }+ \\
\text { Insulin }\end{array}$ & 4 & $143 \pm 31$ & $-72.5 \pm 39$ \\
II $\begin{array}{l}\text { Somatostatin + } \\
\begin{array}{l}\text { Hyperglycaemia }+ \\
\text { Insulin + Glucagon }\end{array}\end{array}$ & 3 & $137 \pm 20$ & $151 \pm 60$ \\
III Saline & 4 & $156 \pm 11$ & $169 \pm 13$ \\
\hline
\end{tabular}

${ }^{a}$ Value from each subject was a mean of 4 consecutive samples at 10 minute intervals during the basal period

b Value from each subject was a mean of $7-8$ consecutive samples at 15 minute intervals during the study period

technique provides reproducible values for EHBF which are in the range predicted by other measurements of hepatic blood flow [9].

For infusion, insulin, glucagon and somatostatin were mixed in $0.154 \mathrm{~mol} / 1$ saline with human serum albumin $(0.5 \mathrm{~g}$ human serum albumin $/ 100 \mathrm{ml}$ ). Human serum albumin was similarly added to the indocyanine green infusate to increase the stability of the latter. Cyclic somatostatin was provided by Dr. Jean Rivier, Salk Institute, La Jolla, Calif. [10].

Plasma glucose was measured in a Beckman Glucose Analyzer (Beckman Instruments, Inc., Fullerton, Calif.). Plasma glucose was converted to whole blood glucose concentration [11] by the formula: whole blood glucose concentration = plasma glucose concentration (1-0.3 haematocrit)/100. Immunoreactive glucagon was assayed with the $30 \mathrm{~K}$ antiserum of Aguilar-Parada et al. [12]. Immunoreactive insulin was assayed by the Sephadex-bound (Pharmacia Fine Chemicals, Inc., Piscataway, N. J.) antibody procedure [13]. The plasma concentrations of indocyanine green were determined in a Beckman spectrophotometer at $810 \mathrm{~nm}$. Net splanchnic glucose production (NSGP) was calculated by multiplying the hepatic venous-arterial blood glucose difference by the estimated hepatic blood flow. Significance was determined by Student's $t$ test where applicable [14]. Results are expressed as mean \pm SEM.

\section{Results}

Effect of Acute Hyperglycaemia on Net Splanchnic Glucose Production (NSGP) with Fixed Low Levels of Insulin and Hypoglucagonaemia

Four normal men received concomitant infusions of somatostatin, insulin $(0.15 \mathrm{mU} / \mathrm{kg} / \mathrm{min})$ and glucose sufficient to raise plasma glucose levels to the range of $220-240 \mathrm{mg} / \mathrm{dl}$ (Figure 1). The mean glucose infusion rate from $30-120$ minutes was $3.57 \pm 0.36 \mathrm{mg} /$ $\mathrm{kg} / \mathrm{min}$. Arterial insulin levels were maintained in the range of 9-12 $\mu \mathrm{U} / \mathrm{ml}$ while glucagon levels declined $44 \%$ from $132 \pm 21$ to $74 \pm 15 \mathrm{pg} / \mathrm{ml}$ (Figure 1 ). Under these conditions NSGP fell from a basal rate of $143 \pm 31$ to a mean rate of $-72 \pm 39 \mathrm{mg} / \mathrm{min}$ and remained suppressed for the duration of the study (Table 1). 
Effect of Acute Hyperglycaemia on Net Splanchnic Glucose Production with Fixed Low Levels of Insulin and Basal Levels of Glucagon

An additional three normal men received concomitant infusions of somatostatin, insulin $(0.15 \mathrm{mU} / \mathrm{kg} /$ $\mathrm{min})$, glucagon $(1.5 \mathrm{ng} / \mathrm{kg} / \mathrm{min})$ and glucose sufficient to raise plasma glucose levels to the range of $220-240 \mathrm{mg} / \mathrm{dl}$. The mean glucose infusion rate from $30-120$ minutes was $1.17 \pm 0.51 \mathrm{mg} / \mathrm{kg} / \mathrm{min}$ which was significantly less than in the previous protocol $(p<0.05)$. Arterial insulin levels were maintained in the range of $7-11 \mu \mathrm{U} / \mathrm{ml}$ while glucagon levels rose from $148 \pm 37$ to $229 \pm 36 \mathrm{pg} / \mathrm{ml}$ at 15 minutes and remained elevated for the remainder of the study (Figure 1). Under these conditions hyperglycaemia caused no significant change in NSGP (137 \pm 20 vs $151 \pm 60 \mathrm{mg} / \mathrm{min}$ ) (Table 1).

\section{Effect of Saline on Net Splanchnic Glucose Production}

In Protocol III four normal men received a saline infusion for 2 hours. The levels of insulin and glucagon, plasma glucose concentration and the rate of net splanchnic glucose production (Figure 2 and Table 1) remained constant throughout the two hour study period.

\section{Discussion}

In 1975 Gerich et al. first reported that somatostatin administration in insulin-treated diabetics markedly improved glucose tolerance after ingestion of a mixed meal [1]. They attributed this phenomenon to the somatostatin-induced suppression of circulating glucagon and suggested that glucagon might play an important role in glucose disposal in the diabetic. This reasoning was consistent with Unger's original hypothesis that the decline in plasma glucagon seen during glucose ingestion could be important in reducing the opposition to insulin-induced hepatic glucose storage [15]. Wahren and Felig [2] demonstrated that somatostatin administration delayed or inhibited gastrointestinal glucose absorption and they hypothesized that the improved glucose tolerance seen after somatostatin administration in diabetic man was due to decreased glucose absorption. More recently, however, Raskin and Unger noted improved glycaemic control in diabetics receiving concomitant somatostatin and insulin therapy, which was reversed by two-thirds by an infusion of glucagon [3].

If glucagon suppression does improve glucose tolerance in insulin-treated diabetics, by what

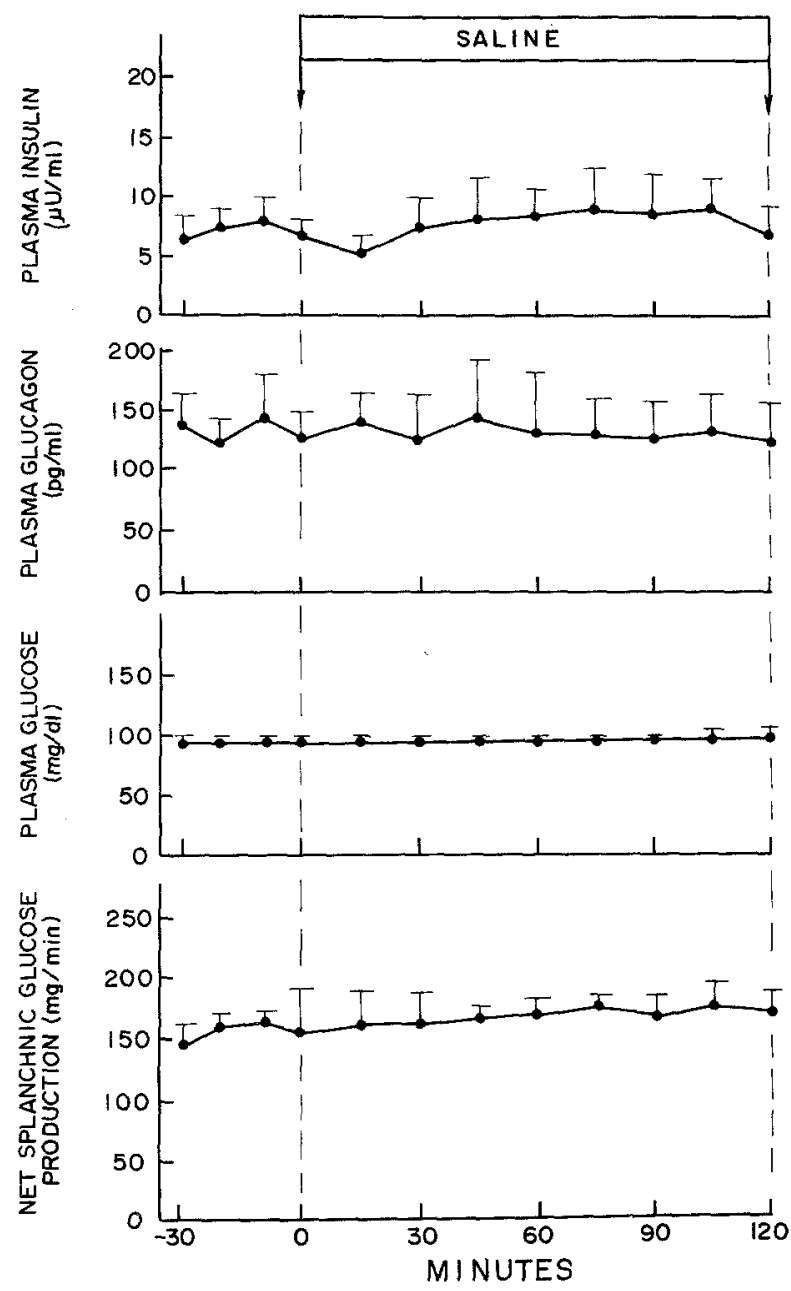

Fig. 2. The effect of saline on arterial plasma insulin, glucagon and glucose concentrations and net splanchnic glucose production in 4 normal men. Bars represent SEM

mechanism does this occur? The present study was designed to examine the hypothesis that glucagon alters the ability of the liver to dispose of a glucose load. This was tested by creating in somatostatintreated, non-diabetic man the metabolic conditions frequently seen in insulin-dependent diabetics, namely hyperglycaemia, accompanied by low levels of insulin. In this setting we could then determine the effects of glucagon on the handling of a glucose load by the splanchnic bed. Our results indicate that under the conditions of the present study a difference in the peripheral plasma glucagon concentration of $154 \mathrm{pg} /$ $\mathrm{ml}(228 \pm 25$ versus $71 \pm 15 \mathrm{pg} / \mathrm{ml})$ changes the metabolic picture dramatically. When hyperglycaemia was induced in the presence of low levels of plasma insulin and with glucagon withdrawn, net splanchnic glucose production fell markedly and net splanchnic glucose uptake of $72 \mathrm{mg} / \mathrm{min}$ occurred. On the other hand, when the same metabolic condi- 
tions were achieved during replacement of glucagon (to mimic basal portal venous glucagon levels) net splanchnic glucose production continued unabated.

The effect on the liver of suppressing plasma glucagon can be examined in another way. In the protocol in which glucagon was withdrawn, $22.9 \mathrm{~g}$ of glucose were infused over the last 90 minutes of the study in order to maintain the predetermined level of hyperglycaemia. In contrast, in the glucagonreplaced subjects, only $7.8 \mathrm{~g}$ were needed over the same time span to maintain the same level of glycaemia. With the plasma levels of insulin and glucose being indistinguishable in the two groups, the amount of glucose infused to maintain the same level of glycaemia becomes a measure of glucose tolerance. Thus, when glucagon was withdrawn, the body was able to dispose of three times more net glucose than when glucagon was replaced. This remarkable difference in glucose tolerance was due to the change in net splanchnic glucose balance depicted in Figure 1. These data thus suggest that when a glucose load is presented to the liver with insulin present but at low level, a situation not uncommon in diabetic man, the plasma glucagon level may determine whether the liver participates in net disposal of the glucose load or whether it continues to add additional net glucose to the circulation.

It should be noted here that the hepatic venous catheter technique measures only net release of glucose from the splanchnic bed and cannot differentiate between hepatic glucose output and uptake. It is possible that in the protocol in which glucagon was replaced de novo hepatic glucose production was stimulated, with simultaneous hyperglycaemiainduced hepatic glucose uptake also occurring, the net result of which was a virtually unchanged rate of net splanchnic glucose production (Figure 1). The classic enzymology studies of Hers [16], however, indicate that almost total inactivation of hepatic phosphorylase is required before glycogen synthase can be activated. Thus, hyperglycaemic suppression of accelerated hepatic glucose production rather than the concomitant occurrence of offsetting rates of glycogen synthesis and breakdown is the most likely explanation of the present data.

The results of the present study are supported by a similar study carried out in our laboratory in conscious dogs [17]. In that study withdrawal of glucagon with basal levels of insulin maintained in the face of hyperglycaemia resulted in marked hepatic glucose storage, which could be prevented by replacement of basal glucagon levels. In the dog study, the induction of hyperglycaemia with insulin and glucagon, both maintained in basal amounts, resulted in a 56\% suppression of net hepatic glucose production, an effect of hyperglycaemia not seen in the present study when glucagon and insulin were both infused. While glucagon was replaced in the present study in amounts designed to mimic the basal portal venous glucagon concentrations, the plasma insulin levels were maintained at levels which would only achieve basal peripheral insulin concentrations, and which would consequently under-replace portal venous insulin concentrations by at least $50 \%$. The apparent lack of a suppressive effect of hyperglycaemia on NSGP noted in the present experiments is most likely due, therefore, to offsetting effects of hyperglycaemia and hypoinsulinaemia at the level of the liver.

Other investigators have questioned the ability of glucagon to influence glucose disposal $[2,17,18]$. Intravenous glucose tolerance in insulin-withdrawn diabetic man was not influenced by somatostatininduced suppression of plasma glucagon [2]. It appears that a certain level of plasma insulin is required for glucagon suppression to produce a sustained fall in hepatic glucose production which fall is only transient if insulin is simultaneously suppressed [4]. Thus the failure of glucagon suppression to alter intravenous glucose tolerance [2] was most likely due to concomitant insulin deficiency in these insulinwithdrawn diabetics. The mechanism by which insulin allows glucagon withdrawal to have a salutary effect on plasma glucose control may relate to the ability of insulin to sensitize the liver to hyperglycaemia. While glucose has been shown in normal rats to have potent effects on both hepatic glycogen phosphorylase and synthase $[19,20]$, Miller has recently reported that these enzymes were insensitive to glucose in insulin-withdrawn diabetic rats [21]. Insulin replacement for $2 \mathrm{~h}$ prior to study restored sensitivity to glucose.

While glucagon suppression during hyperglycaemia can affect glucose disposal when insulin is present in only small amounts, as seen in the present study, glucagon does not appear to affect glucose disposal when insulin is secreted normally in response to a glucose load. The induction of plasma glucagon levels of $350 \mathrm{pg} / \mathrm{ml}$ during oral glucose tolerance testing was without effect on the plasma glucose response [22]. Thus, in insulin-sensitive normal man the hyperinsulinaemia and hyperglycaemia which attend glucose ingestion combine to override any antagonistic effect physiologic levels of glucagon might have on the liver to block hepatic glucose storage. It would appear, therefore, that lowering plasma glucagon levels may only have beneficial effects in lowering plasma glucose levels if insulin is present, but in less than normal amounts, a condition frequently seen in insulin-treated diabetic man [23]. Recently, it has been suggested that the liver takes up more glucose when glucose is administered orally as compared to when given intravenously [24]. If this 
hypothesis proves correct, the role of glucagon demonstrated in the present paper in substantially altering the hepatic handling of an intravenous glucose load should be re-examined after oral glucose administration.

In conclusion, the present data support a substantial role for glucagon in determining the hepatic response to an intravenous glucose load when insulin is present in less than adequate amounts.

Acknowledgements. We would like to acknowledge gratefully the excellent technical skills of Ray Lamb, Barbara Santoro, and Susan Fulcher and the secretarial help of Carolyn Sielbeck.

The studies outlined in this paper were supported by the following grants: NIAMDD 5 R01 AM 19587, NIH AM 18243, and USPHS Grant 5M01 RR-05 from the General Clinical Research Centers Branch of the Division of Research Resources, National Institutes of Health.

Dr. Liljenquist is an investigator of the Howard Hughes Medical Institute.

Dr. Cherrington is a recipient of the Research and Career Development Award from the National Institutes of Health, 1977-1978, 1 K04 AM 00480.

\section{References}

1. Gerich, J. E., Lorenzi, M., Schneider, V., Karam, J. H., Rivier, J., Guillemin, R., Forsham, P. H.: Effects of somatostatin on plasma glucose and glucagon levels in human diabetics mellitus. Pathophysiologic and therapeutic implications. N. Engl. J. Med. 291, 544-547 (1974)

2. Wahren, J., Felig, P.: Influence of somatostatin on carbohydrate disposal and absorption in diabetes mellitus. Lancet 1976 II, 1213-1216

3. Raskin, P., Unger, R. H.: Hyperglucagonemia and its suppression. N. Engl. J. Med. 299, 433-436 (1978)

4. Liljenquist, J. E., Mueller, G. L.,Cherrington, A. D., Keller, U., Chiasson, J. L., Perry, J. M., Lacy, W. W., Rabinowitz, D.: Evidence for an important role of glucagon in the regulation of hepatic glucose production in normal man. J. Clin. Invest. 59, 369-374 (1977)

5. Pozefsky, T., Tancredi, R. G., Moxley, R. T., Dupré, J., Tobin, J.D.: Metabolism of forearm tissues in man. Studies with glucagon. Diabetes 25, 128-135 (1976)

6. Chiasson, J. L., Liljenquist, J. E., Sinclair-Smith, B. C., Lacy, W. W.: Gluconeogenesis from alanine in normal postabsorptive man. Intrahepatic stimulatory effect of glucagon. Diabetes 24, 574-584 (1974)

7. Andres, R., Swerdloff, R. S., Pozefsky, T., Coleman, D.: Manual feedback technique for control of blood glucose concentration. In: Automation in analytical chemistry. Skeggs, L. J., Jr. (Ed.), pp. 486-491. New York: Mediad Inc. 1966

8. Leevy, C. M., Mendenhall, C. L., Lesko, W., Howard, M. M.: Estimation of hepatic blood flow with indocyanine green. $\mathrm{J}$. Clin. Invest. 41, 1169-1179 (1962)

9. Greenway, C. V., Stark, R. D.: Hepatic vascular bed. Physiol. Rev. 51, 23-65 (1971)

10. Rivier, J., Kaiser, R., Galyean, R.: Solid phase synthesis of somatostatin and glucagon-selective analogs in gram quantities. Biopolymers 17, 1927-1938 (1978)

11. Dillon, R. S.: Importance of the hematocrit in interpretation of blood sugar. Diabetes 14, 672-674 (1965)
12. Aguilar-Parada, A. M., Eisentraut, I, Unger, R. H.: Pancreatic glucagon secretion in normal and diabetic subjects. Am. J. Med. Sci. 275, 415-419 (1969)

13. Wide, L., Porath, J.: Radioimmunoassay of proteins with the use of Sephadex-coupled antibodies. Biochim. Biophys. Acta 130, 257-260 (1966)

14. Snedecor, G. W.: Statistical methods applied to experiments in agriculture and biology. p. 35. Ames, Iowa: Iowa State University 1956

15. Unger, R. H., Lefebvre, P. J.: Glucagon physiology. In: Glucagon. Lefebvre, P. J., Unger, R. H., (Eds.), pp. 213-244. New York: Pergamon Press 1972

16. Hers, H. G.: The control of glycogen metabolism in the liver. Annu. Rev. Biochem. 45, 167-189 (1976)

17. Shulman, G. I., Liljenquist, J. E., Williams, P. E., Lacy, W. W., Cherrington, A. D.: Glucose disposal during insulinopenia in somatostatin-treated dogs. The roles of glucose and glucagon. J. Clin. Invest. 62, 487-491 (1978)

18. Sherwin, R. S., Fisher, M., Hendler, R., Felig, P.: Hyperglucagonemia and blood glucose regulation in normal, obese, and diabetic subjects. N. Engl. J. Med. 294, 455-461 (1976)

19. Barnes, A. J., Bloom, S. R.: Pancreatectomized man: a model for diabetes without glucagon. Lancet 1976 I, 219-221

20. Hue, L., Bontemps, F., Hers, H. G.: The effect of glucose and of potassium ions on the interconversion of the two forms of glycogen phosphorylase and of glycogen synthetase in isolated rat liver preparations. Biochem. J. 152, 105-114 (1975)

21. Miller, T.B., Jr.: Effects of diabetes on glucose regulation of enzymes involved in hepatic glycogen metabolism. Am. J. Physiol. 234, E13-E19 (1978)

22. Liljenquist, J. E., Rabinowitz, D.: Lack of a role for glucagon in the disposal of an oral glucose load in normal man. J. Clin. Endocrinol. Meab. (In press)

23. Ginsberg, S., Block, M. B., Mako, M. E., Rubenstein, A. H.: Serum insulin levels following administration of exogenous insulin. J. Clin. Endocrinol. Metab. 36, 1175-1179 (1973)

24. DeFronzo, R. A., Ferrannini, E., Hendler, R., Wahren, J., Felig, P.: Influence of hyperinsulinemia, hyperglycemia, and the route of glucose administration on splanchnic glucose balance. Proc. Natl. Acad. Sci. USA 75, 5173-5177 (1978)

25. Raskin, P., Unger, R.H.: Effects of exogenous hyperglucagonemia in insulin-treated diabetics. Diabetes $\mathbf{2 6}$, 1034-1039 (1977)

26. Gerich, J. E., Schultz, T. A., Lewis, S. B., Karam, J. H.: Clinical evaluation of somatostatin as a potential adjunct to insulin in the management of diabetes mellitus. Diabetologia 13, 537-544 (1977)

27. Christensen, J. E., Hansen, A. P., Weeke, J., Lundbaek, K. 24-hour studies of the effects of somatostatin on the levels of plasma growth hormone, glucagon, and glucose in normal subjects and juvenile diabetics. Diabetes 27, 300-306 (1978)

28. Tamborlane, W.V., Sherwin, R. S., Hendler, R., Felig, P.: Metabolic effects of somatostatin in maturity-onset diabetes. N. Engl. J. Med. 297, 181-183 (1977)

29. Christensen, S. E., Hansen, Aa. P., Lundbaek, K.: Somatostatin in maturity-onset diabetes. Diabetes 27, 1013-1019 (1978)

Received: November 21, 1978, and in revised form: April 23, 1979

John E. Liljenquist, M. D.

Associate Professor of Medicine

Howard Hughes Medical Institute Laboratory

Vanderbilt University Medical Center

Nashville, TN 37232

USA 